\title{
Phenotypic Screening and Evaluation of Sub1 Introgressed Lines in Popular Rice Varieties Ranjit and Bahadur of Assam, India
}

\author{
Ashish Gautam ${ }^{1 *}$, S.K. Chetia ${ }^{2}$, M.K. Modi ${ }^{3}$ and T. Ahmed ${ }^{2}$ \\ ${ }^{1}$ Department of Plant Breeding and Genetics, ${ }^{3}$ Department of Agricultural Biotechnology, \\ AAU, Jorhat-785013, Assam, India \\ ${ }^{2}$ Regional Agricultural Research Station, AAU, Titabar, Assam, India \\ *Corresponding author
}

\section{Keywords}

Bahadur, Phenotyping,

Ranjit, Rice, $S u b 1$,

Submergence tolerance

Article Info

Accepted:

12 August 2018

Available Online:

10 September 2018

\section{A B S T R A C T}

Phenotypic screening during kharif 2015 and evaluation of Subl introgressed lines in Ranjit and Bahadur for submergence tolerance was done with the 35 genotypes. Out of 35 genotypes 32 were $S u b 1$ introgressed $\mathrm{BC}_{2} \mathrm{~F}_{3}$ lines $\left(24 \mathrm{BC}_{2} \mathrm{~F}_{3}\right.$ lines of the cross -Ranjit $\mathrm{x}$ Swarna-Subland $8 \mathrm{BC}_{2} \mathrm{~F}_{3}$ lines of the cross -Bahadur $\mathrm{x}$ Swarna-Subl) with three parents i.e. Ranjit, Bahadur, and Swarna-Subl. The phenotypic screening of genotypes showed that all Subl introgressed lines had significantly higher survival rates as compared with the original recipient parents whereas less change in plant height was observed. The Subl introgressed lines in $\mathrm{BC}_{2} \mathrm{~F}_{3}$ generation showed lesser elongation during submergence as compared to the parents and the susceptible check IR42. The analysis of variance revealed the existence of significant variation among the genotypes for grain yield and all other morpho-physiological quantitative traits. High estimates of genotypic and phenotypic variation in case of morphological characters like stem thickness, panicle number per plant indicated that selection would be effective for these characters. Amongst all the morphophysiological quantitative traits, high heritability $(>80)$ with high genetic advance $(>20)$ as percent of mean estimates were recorded for leaf length of blade, stem thickness, leaf width of blade, grain weight of 1000 fully developed grains and grain width. The high estimates of heritability for these characters also indicated considerable genetic variation and lower influence of environment in the expression of these characters. High genetic advance coupled with high heritability estimates indicates that these traits are apparently controlled by additive genes. Thus these traits deserve top most priority in selection.

\section{Introduction}

Rice (Oryza sativa L.) is the staple food of more than half of the world population. It is the dominant and only suitable crop in the rainfed and lowland areas of India. Submergence stress is a major constraint to rice production in areas of high rainfall and it adversely affects farmers living on 10-15 million hectares of rainfed lowland rice in South and Southeast Asia (Neeraja et al., 2007). To meet the demand of the ever increasing global population, greater production of rice is needed from this flood prone ecosystem. According to the estimate of World Bank (World Bank, 2008), flood 
affected areas increased to 40 million hectares from 19 million hectares within one decade in India. Short-term submergence regularly affects over 20 million ha of rice in the tropic (Mackill et al., 2012).

Assam is one of the major rice growing states in the country and Sali rice is grown as rainfed crop and it occupies around 1.8 million hectares. Around 0.5 million hectares Sali rice growing areas are chronically affected by flood. Flood is the major problem in the state, which affect all the three classes of rice. Sali rice is damaged in its vegetative stage due to inundation of low lying areas. Nearly 4 lakh hectares rice is chronically flood prone and the flood affected area is around 10 lakh hectares. Submergence due to inundation causes mortality of tillers and the extent of yield loss depends on the intensity and the duration of flood. Hence, sustainable and permanent solutions are needed to overcome this problem. One of the most promising solutions is to develop high yielding varieties that are submergence tolerant and that are more likely to be rapidly adopted by farmers in the target regions (Septiningsih et al., 2009). Submergence tolerance is controlled by a single major quantitative trait locus (QTL) on chromosome 9, along with a number of minor QTLs (Xu and Mackill, 1996). All these studies have used the landrace FR13A (Nandi et al., 1997; $\mathrm{Xu}$ and Mackill, 1996) which is one of the most submergence-tolerant donor varieties. Swarna-Subl as well as other Subl introgressed varieties such as Samba MahsuriSub1, IR 64-Sub1, BR 11-Sub1, CR 1009Subland TDK-Subl is not adopted by the farmers of the state as they prefer the agronomic qualities of the variety Ranjit and Bahadur. Ranjit and Bahdur (semi-tall varieties) are the most popular varieties of Assam and they cover about 65 per cent of Sali rice growing areas in the state. However, these varieties are not tolerant to submergence. Thus, development of Subl
QTL introgressed submergence tolerant version of these varieties i.e. Ranjit-Subl and Bahadur-Subl will definitely help the farmers of the flood prone areas of Assam. Hence, the present investigation has been undertaken with the objective phenotypic screening and evaluation of Subl introgressed lines for submergence tolerance.

\section{Materials and Methods}

The present study was undertaken with the aim of evaluation of Subl introgressed lines for submergence tolerance in Ranjit and Bahadur. Ranjit and Bahadur are popular rice varieties of Assam covering more than 60 percent area during kharif. Field experiments were conducted during Sali/Kharif 2015 at Regional Agriculture Research Station (RARS), Assam Agricultural University, Titabar, Assam, India. The experimental material comprised of 32 Subl introgressed $\mathrm{BC}_{2} \mathrm{~F}_{3}$ lines (24 Subl introgressed lines in Ranjit background and 8 Subl introgressed lines in Bahadur background). Rice genotypes having tolerance to submergence namely Swarna-Subland FR13A were used as resistant check variety and Swarna, Ranjit, Bahadur and IR42 were used as susceptible check variety in phenotypic screening.

\section{Screening for submergence tolerance}

Phenotyping of the 32 Subl fixed lines for submergence tolerance were carried out during Sali/Kharif 2015 (Table 1). Phenotypic screening was carried out in phenotypic tank of dimension $(10.0 \mathrm{~m}$ X $10.0 \mathrm{~m}$ X $2.0 \mathrm{~m})$. The seeds of the $S u b 1$ introgressed lines along with the checks were sown into the tank. The 10 days old seedlings were then submerged for 12 days and water level was maintained at 1.1 m. Desubmergence was carried out after 12 days and the genotypes were assessed on the basis of survival percentage and plant height (elongation ability). 


\section{Evaluation of Sub1 introgressed lines}

The lines were evaluated on the basis of yield and other morpho-physiological quantitative characters by using experimental design RBD (Table 2). The mean values of the observations recorded for 38 genotypes using CRD experimental design were subjected to the statistical and biometrical analyses. The partitioning of the total variance assignable to different sources was done according to Fisher's method. Genetic parameters were estimated for each character from ANOVA. The mean data for each of the eleven morphophysiological characters were subjected to analysis of variance by following randomized block design. Genetic parameters were estimated for each character from ANOVA. Genotypic variances $\left(\sigma_{\mathrm{g}}^{2}\right)$, phenotypic variance $\left(\sigma_{\mathrm{p}}^{2}\right)$ and environmental variance $\left(\sigma_{\mathrm{e}}^{2}\right)$ were computed according to Burton and Devane (Burton and Devane, 1953). Genotypic coefficient of variation (GCV) and phenotypic coefficient of variation (PCV) were estimated from these variances in terms of standard deviation as percentage of the grand mean. Heritability $\left(h^{2}\right)$ in broad sense was calculated following Allard (Allard, 1960). Expected genetic advance for each character was calculated by using the formula suggested by Hanson (Hanson et al., 1956).

\section{Results and Discussion}

\section{Phenotyping}

The phenotypic screening of the 32 genotypes along with resistant check verities i.e. SwarnaSubl and FR13A and susceptible check varieties i.e. Swarna, Ranjit, Bahadur and IR42 have shown that all Subl introgressed lines had significantly higher survival rates as compared with the original recipient parents and less change in plant height was observed. Further it was observed that the Subl introgressed lines in $\mathrm{BC}_{2} \mathrm{~F}_{3}$ generation showed lesser elongation during submergence compared to the parents and the susceptible check IR42. The Sub1 introgressed lines have shown survival rate in between the range 7892 percent whereas the susceptible cultivars showed 0-24 percent and resistant check cultivars showed survival percentage in the range of 83-91 (Table 3). The plant height before survival in Subl introgressed lines rages from 19-28 percent whereas plant height after survival in Subl introgressed lines ranges from 22-34 percent. In case of resistant check variety the plant height before survival rages from 20-34 and plant height after survival ranges from 26-40 (Fig. 2). In susceptible check cultivars the plant height before survival was recorded in the range of 20-23 and plant height after survival was found 0-38. The Subl introgressed lines have shown elongation rate (plant height) in between the ranges 7.40 32.00 percent whereas the susceptible cultivars showed 0-65.21 percent and in resistant check cultivars it was found in range of 17.64-30 percent. Based on the observed data the $C D$ value for survival percentage was found to be 4.12 and for percentage change in plant height was 2.33 at 5 percent probability level.

\section{Evaluation of Sub1 introgressed lines}

The evaluation of Subl introgressed lines was done with eleven quantitative characters by using experimental design RBD. The rice genotypes were distinguished from each other in respect of length of leaf blade (LLB) which ranged from $29.5 \mathrm{~cm}$ in Swarna-Sub1 to 61.53 $\mathrm{cm}$ in E-6 genotype with a mean value $42.11 \mathrm{~cm}$. The genotypes exhibited less variability $(\mathrm{CV}=0.97)$. Leaf width $(\mathrm{LWdB})$ ranged from $1.08 \mathrm{~cm}$ in Ranjit to $1.98 \mathrm{~cm}$ in genotype 1189-1 with a mean value $1.64 \mathrm{~cm}$. The genotypes exhibited more variability $(\mathrm{CV}=2.44)$. Stem thickness (ST), which ranged from $0.45 \mathrm{~cm}$ in $\mathrm{W}-167$ to $1.56 \mathrm{~cm}$ in $\mathrm{N}-3$ genotype with a mean value $0.62 \mathrm{~cm}$. The 
genotypes exhibited more variability $(\mathrm{CV}=$ 9.88). Stem length (SL), which ranged from $79.16 \mathrm{~cm}$ in D-160 and $130.166 \mathrm{~cm}$ in $1189-1$ genotype with a mean value $102.26 \mathrm{~cm}$. The genotypes exhibited more variability $(\mathrm{CV}=1.14)$. The rice genotypes were distinguished from each other in respect of panicle number per plant (PNP), which ranged from 3 in N-3 and 13 in U-86 genotype with a mean value of 8.73 . The genotypes exhibited more variability $(\mathrm{CV}=14.77)$. Grain weight of 1000 fully developed grains (GW) which ranged from $11.56 \mathrm{~g}$ in $\mathrm{L}-3$ to $22.83 \mathrm{~g}$ in Bahadur genotype with a mean value of 17.35 g. The genotypes exhibited more variability $(\mathrm{CV}=1.54)$. Grain length (GL) which ranges from $7.19 \mathrm{~mm}$ in $1398-1$ to $8.40 \mathrm{~mm}$ in 1324 1 genotypes with a mean value of $7.76 \mathrm{~mm}$. The genotypes exhibited variability $(\mathrm{CV}=$ 2.15). Grain width (GWd) which ranged from $1.42 \mathrm{~mm}$ in $\mathrm{J}-164$ to $2.32 \mathrm{~mm}$ in the genotype Swarna-Subl with a mean value of $1.64 \mathrm{~mm}$. The genotypes exhibited variability $(\mathrm{CV}=$ 2.02). Decorticated grain length (DGL) which ranged from $4.77 \mathrm{~mm}$ in D-160 to $5.89 \mathrm{~mm}$ in N-3 genotype with a mean value $5.49 \mathrm{~mm}$. The genotypes exhibited more variability $(\mathrm{CV}=$ 3.69). Decorticated grain width (DGWd) which ranged from $1.27 \mathrm{~mm}$ in $\mathrm{C}$ 210 and D-136 to $1.92 \mathrm{~mm}$ in Bahadur genotype with a mean value $1.45 \mathrm{~mm}$. The genotypes exhibited variability $(\mathrm{CV}=2.35)$. Yield per plot which ranged from $3.13 \mathrm{~kg}$ in D-136 to $6.25 \mathrm{Kg}$ in Bahadur. Remaining cultivars fell between these ranges. The genotypes exhibited more variability $(\mathrm{CV}=$ 9.80). The significant difference was found for all the eleven quantitative characters under study.

\section{Analysis of variance for eleven morpho- physiological characters}

Analysis of variance (ANOVA) for eleven morpho-physiological quantitative characters are presented in (Table 4). The results showed that the mean sum of squares were highly significant for all the characters. It means that there is sufficient variability among the different genotypes and hence desirable improvement can be brought through selection for different characters. There were significant differences among the genotypes for all the characters under study.

\section{Extent of genetic variation for eleven morpho-physiological characters}

The estimates of genotypic and phenotypic variances, heritability, genotypic and phenotypic coefficients of variations, genetic advance as a percentage of mean and expected genetic advance at 5 percent selection intensity are presented in (Table 5). In case of morpho-physiological characters a comparison of the genotypic and phenotypic variances of the characters clearly revealed that there was a close correspondence between the two estimates for all the characters. A better comparison of the extent of genetic variation in the traits could be made from the estimates of genotypic and phenotypic coefficients of variations. The GCV estimate for yield was found to be 13.57 percent which were moderate. The maximum GCV was reflected for stem thickness (30.07) followed by panicle number per plant (20.44) (Fig. 1). The lowest GCV was reflected for grain length (4.30) followed by decorticated grain length (4.73) and stem length (9.32). Rest of the characters exhibited moderate GCV. For these characters GCV estimates had a close correspondence with PCV estimates along with their high heritability estimates. Highest heritability with genetic advance was observed for leaf length of blade $(99.76,41.13)$, stem thickness $(89.74$, $58.69)$, leaf width of blade (97.16, 32.44), grain weight of 1000 fully developed grains $(98.83,28.97)$ and grain width $(97.22,23.12)$ (Fig. 2). High heritability with moderate genetic advance was observed for the traits like stem length $(98.51,19.06)$ and 
decorticated grain width (95.58, 20.44). Moderate heritability with low genetic advance was observed for the traits like grain length $(79.95,7.93)$, and decorticated grain length $(62.26,7.69)$. Moderate heritability with high genetic advance was observed for the traits like yield $(65.79,22.67)$ and panicle number per plant $(65.79,34.14)$. The genetic advance as percentage of mean was observed at $5 \%$ selection intensity.

Fig.1 Genetic variability parameters (Mean, GCV, PCV) of eleven quantitative morphophysiological characters viz. Leaf Length of blade (LLB), Leaf width of blade (LWdB), Stem thickness (ST), Stem length (SL), Panicle number per plant (PNPP), Grain weight of 1000 fully developed grains (GW), Grain length (GL), Grain width (GWd), Decorticated grain length (DGL), Decorticated grain width (DGWd), Yield

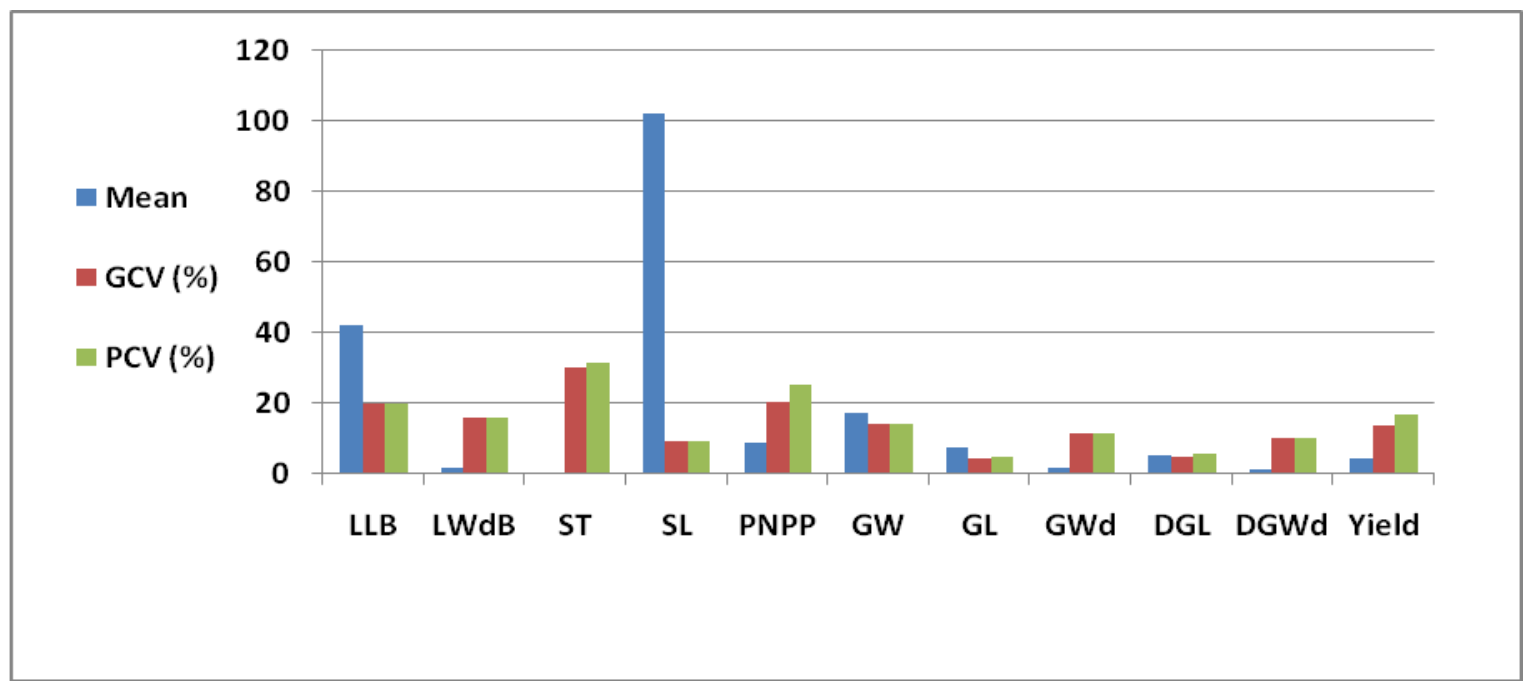

Fig. 2 Genetic variability parameters $\left(\mathrm{h}^{2}{ }_{\mathrm{bs}}\right.$, $\mathrm{GA}$ (\% of mean) of eleven quantitative morphophysiological characters viz. Leaf Length of blade (LLB), Leaf width of blade (LWdB), Stem thickness (ST), Stem length (SL), Panicle number per plant (PNPP), Grain weight of 1000 fully developed grains (GW), Grain length (GL), Grain width (GWd), Decorticated grain length

(DGL), Decorticated grain width (DGWd), Yield

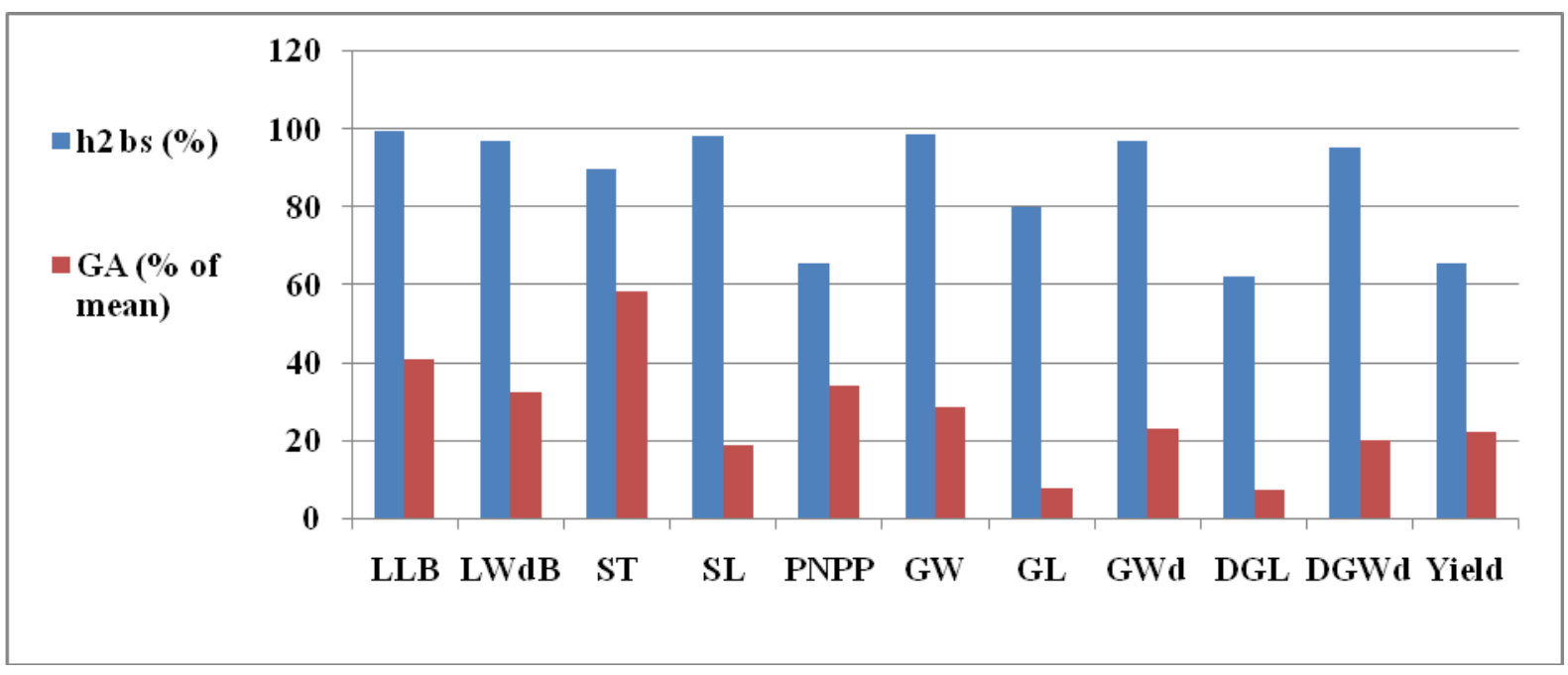


Table.1 List of genotypes used in the present study

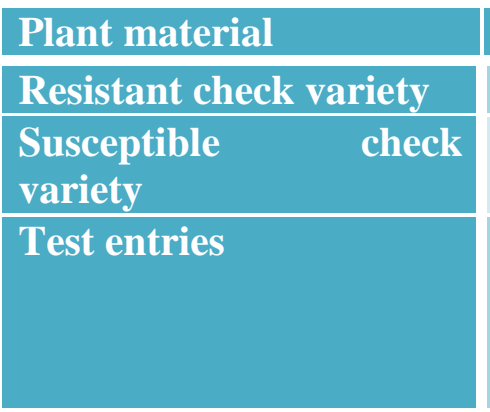

\section{Genotypes}

Swarna-Subl, FR13A

IR 42, Swarna, Ranjit, Bahadur

Y-374, C-210, 1160-2, Y-219, N-6, S-4, 1160-1, N-9, 1316-2, W167, J-329, C-376, Y-350, L-2, C-196, U-86, N-3, J-164, L-3, D160, C-367, Z-1, E-6, D-65, Z-8, D-136, A-193, 1241-1, 1189-1, 1324-1, 1398-1, 1384-1.

Table.2 List of quantitative morpho-physiological characters used in evaluation of Sub1 introgressed lines

\begin{tabular}{|l|l|l|l|}
\hline $\begin{array}{l}\text { SI. } \\
\text { No }\end{array}$ & $\begin{array}{l}\text { Morpho-physiological } \\
\text { quantitative characters }\end{array}$ & $\begin{array}{l}\text { SI. } \\
\text { No }\end{array}$ & $\begin{array}{l}\text { Morpho-physiological quantitative } \\
\text { characters }\end{array}$ \\
\hline 1. & Leaf length of blade $(\mathrm{cm})$ & 8. & Grain width $(\mathrm{mm})$. \\
\hline 2. & Leaf width of blade $(\mathrm{cm})$. & 9. & Decorticated grain length $(\mathrm{mm})$. \\
\hline 3. & Stem thickness $(\mathrm{cm})$. & 10. & Decorticated grain width $(\mathrm{mm})$. \\
\hline 4. & Stem length $(\mathrm{cm})$. & 11. & Yield \\
\hline 5. & Panicle no per plant. & 6. & $\begin{array}{l}\text { Grain weight of } 1000 \text { fully developed } \\
\text { grains }(\mathrm{gm}) .\end{array}$ \\
\hline 7. & Grain length $(\mathrm{mm})$. & &
\end{tabular}

Table.3 Survival percentage and percentage changes in plant height due to submergence of the rice cultivars after 12 days of submergence

\begin{tabular}{|c|c|c|c|c|}
\hline \multirow[t]{2}{*}{ Test Entries } & \multirow{2}{*}{$\begin{array}{l}\text { Survival } \\
\text { Percentage }\end{array}$} & \multicolumn{3}{|c|}{ Plant Height } \\
\hline & & $\begin{array}{c}\text { Before } \\
\text { Survival }(\mathrm{cm})\end{array}$ & $\begin{array}{c}\text { After } \\
\text { Survival }(\mathrm{cm})\end{array}$ & $\begin{array}{l}\text { Percentage } \\
\text { Change }\end{array}$ \\
\hline IR 42 & 0 & 21 & - & - \\
\hline FR 13A & 91 & 34 & 40 & 17.64 \\
\hline Swarna Subl & 83 & 20 & 26 & 30.00 \\
\hline Swarna & 14 & 20 & 33 & 65.00 \\
\hline Ranjit & 20 & 23 & 36 & 56.52 \\
\hline Bahadur & 24 & 23 & 38 & 65.21 \\
\hline Y-374 & 83 & 19 & 23 & 21.05 \\
\hline C-196 & 87 & 25 & 33 & 32.00 \\
\hline E-6 & 88 & 25 & 31 & 24.00 \\
\hline C-210 & 83 & 24 & 30 & 25.00 \\
\hline U-86 & 85 & 23 & 28 & 21.73 \\
\hline 1189-1 & 90 & 27 & 31 & 14.81 \\
\hline
\end{tabular}




\begin{tabular}{|c|c|c|c|c|}
\hline $1160-2$ & 89 & 24 & 28 & 17.05 \\
\hline $\mathrm{N}-3$ & 78 & 24 & 31 & 29.16 \\
\hline $1324-1$ & 87 & 22 & 28 & 27.27 \\
\hline Y-219 & 83 & 21 & 27 & 28.57 \\
\hline J-164 & 90 & 28 & 34 & 21.42 \\
\hline 1398-1 & 92 & 23 & 29 & 25.00 \\
\hline N-6 & 89 & 24 & 29 & 20.83 \\
\hline L-3 & 91 & 19 & 22 & 15.78 \\
\hline D-65 & 88 & 28 & 33 & 17.85 \\
\hline S-4 & 87 & 23 & 27 & 17.39 \\
\hline D-160 & 84 & 26 & 30 & 15.38 \\
\hline Z-8 & 81 & 22 & 26 & 18.18 \\
\hline $1160-1$ & 85 & 26 & 30 & 14.06 \\
\hline C-367 & 89 & 20 & 24 & 20.00 \\
\hline D-136 & 90 & 27 & 29 & 7.40 \\
\hline N-9 & 88 & 23 & 29 & 26.08 \\
\hline Z-1 & 85 & 21 & 24 & 14.28 \\
\hline 1384-1 & 84 & 24 & 28 & 16.66 \\
\hline $1316-2$ & 86 & 26 & 31 & 19.23 \\
\hline L-2 & 81 & 22 & 25 & 13.63 \\
\hline A-193 & 79 & 23 & 28 & 21.73 \\
\hline W-167 & 88 & 21 & 23 & 9.52 \\
\hline Y-350 & 81 & 22 & 24 & 9.09 \\
\hline 1241-1 & 82 & 25 & 33 & 32.00 \\
\hline $\mathrm{J}-329$ & 86 & 24 & 28 & 16.66 \\
\hline C-376 & 83 & 22 & 25 & 13.63 \\
\hline $\mathrm{CD}(0.05)$ & 4.12 & & & 2.33 \\
\hline
\end{tabular}

Table.4 Analysis of variance (Mean squares) for eleven quantitative morpho-physiological characters

\section{Mean squares}

\begin{tabular}{|r|l|l|l|l|l|l|l|l|l|l|l|l|}
$\begin{array}{c}\text { Source of } \\
\text { variance }\end{array}$ & D.F & LLB & LWdB & ST & SL & PNPP & GW & GL & GWd & DGL & DGWd & Yield \\
\hline Replication & 2 & 0.41 & $0.01 * *$ & 0.01 & $19.84 * *$ & $15.72 * *$ & $0.64 * *$ & $0.36 * *$ & $0.02 * *$ & $0.30^{* *}$ & $0.01 * *$ & 0.16 \\
\hline Genotypes & 34 & $212.85^{* *}$ & $0.20^{* *}$ & $0.10^{* *}$ & $274.05^{* *}$ & $11.23 * *$ & $18.15^{* *}$ & $0.36 * *$ & $0.10^{* *}$ & $0.24 * *$ & $0.06 * *$ & $1.35 * *$ \\
\hline Error & 68 & 0.16 & 0.002 & 0.004 & 1.36 & 1.66 & 0.071 & 0.02 & 0.001 & 0.04 & 0.001 & 0.20 \\
\hline
\end{tabular}

*Significant at $\mathrm{p}=0.005 \quad * *$ Significant at $\mathrm{p}=0.001$

Leaf Length of blade (LLB), Leaf width of blade (LWdB), Stem thickness (ST), Stem length (SL), Panicle number per plant (PNPP), Grain weight of 1000 fully developed grains (GW), Grain length (GL), Grain width (GWd), Decorticated grain length (DGL), Decorticated grain width (DGWd), Yield. 
Table.5 Genetic variability parameters of eleven quantitative morpho-physiological characters

\begin{tabular}{|c|c|c|c|c|c|c|c|c|c|}
\hline \multirow[t]{2}{*}{ Characters } & \multicolumn{2}{|c|}{ Range } & \multirow[t]{2}{*}{ Mean } & \multirow[t]{2}{*}{$\left(\sigma_{g}^{2}\right)$} & \multirow[t]{2}{*}{$\left(\sigma_{p}^{2}\right)$} & \multirow{2}{*}{$\begin{array}{c}\text { GCV } \\
(\%)\end{array}$} & \multirow{2}{*}{$\begin{array}{r}\text { PCV } \\
(\%)\end{array}$} & \multirow{2}{*}{$\begin{array}{l}\mathbf{h}^{2}{ }_{\mathrm{bs}} \\
(\%)\end{array}$} & \multirow{2}{*}{$\begin{array}{c}\text { GA }(\% 0 \\
\text { mean) }\end{array}$} \\
\hline & Min. & Max. & & & & & & & \\
\hline LLB & 29.5 & 61.53 & 42.11 & 70.89 & 71.06 & 19.99 & 20.01 & 99.76 & 41.13 \\
\hline LWdB & 1.08 & 1.98 & 1.64 & 0.06 & 0.07 & 15.97 & 16.20 & 97.16 & 32.44 \\
\hline ST & 0.45 & 1.56 & 0.62 & 0.03 & 0.039 & 30.07 & 31.74 & 89.74 & 58.69 \\
\hline SL & 79.16 & 130.16 & 102.2 & 90.89 & 92.26 & 9.32 & 9.39 & 98.51 & 19.06 \\
\hline PNPP & 3 & 13 & 8.73 & 3.18 & 4.85 & 20.44 & 25.22 & 65.69 & 34.14 \\
\hline GW & 11.56 & 22.83 & 17.35 & 6.02 & 6.09 & 14.14 & 14.23 & 98.83 & 28.97 \\
\hline GL & 7.19 & 8.40 & 7.76 & 0.11 & 0.13 & 4.30 & 4.81 & 79.95 & 7.93 \\
\hline$\overline{\text { GWd }}$ & 1.42 & 2.32 & 1.64 & 0.035 & 0.036 & 11.38 & 11.54 & 97.22 & 23.12 \\
\hline DGL & 4.77 & 5.89 & 5.49 & 0.06 & 0.10 & 4.73 & 5.99 & 62.26 & 7.69 \\
\hline DGWd & 1.27 & 1.92 & 1.45 & 0.021 & 0.022 & 10.15 & 10.38 & 95.58 & 20.44 \\
\hline Yield & 3.13 & 6.25 & 4.57 & 0.38 & 0.58 & 13.57 & 16.73 & 65.79 & 22.67 \\
\hline
\end{tabular}

Leaf Length of blade (LLB), Leaf width of blade (LWdB), Stem thickness (ST), Stem length (SL), Panicle number per plant (PNPP), Grain weight of 1000 fully developed grains (GW), Grain length (GL), Grain width (GWd), Decorticated grain length (DGL), Decorticated grain width (DGWd), Yield.

Phenotyping and evaluation of Sub1 introgressed lines

\section{Phenotyping}

The present study clearly demonstrated that all the Subl introgressed lines exhibited significantly higher survival rates compared to the parents. Further it was observed that the Subl introgressed lines in $\mathrm{BC}_{2} \mathrm{~F}_{3}$ generation showed lesser elongation during submergence compared to the parents and the susceptible check IR42. The Sub1 introgressed lines have shown survival rate in between the range 7892 percent whereas the susceptible cultivars showed 0-24 percent and resistant check cultivars showed survival percentage in the range of 83-91 these results are in accordance with Iftekharuddaula et al., (2016), Singh et al., (2016), Jena et al., (2015) and John et al., (2017). The plant height before survival in Sub1 introgressed lines rages from 19-28 percent whereas plant height after survival in Sub1 introgressed lines ranges from 22-34 percent. In case of resistant check variety the plant height before survival rages from 20-34 and plant height after survival ranges from
26-40. In susceptible check cultivars the plant height before survival was recorded in the range of 20-23 and plant height after survival was found 0-38. The Sub1 introgressed lines have shown elongation rate in between the range 7.40-32.00 percent whereas the susceptible cultivars showed 0-65.21 percent and in resistant check cultivars it was found in range of 17.64-30 percent. The result corroborated with Sarkar et al., (1996), Das et al., (2005), Septiningsih et al., (2009), Jena et al., (2015) and Goswami et al., (2017). Jena et al., (2015) reported that in the submergence screening more than $75 \%$ survival rate was observed in the $\mathrm{BC}_{2} \mathrm{~F}_{2}$ generation Subl introgressed lines in two popular semi lowland rice cultivars Pooja and Pratikshya of Orissa. A similar study was made by Septiningsih et al., (2009) where it was observed that all mega varieties with Subl introgression had a significantly higher survival rate than the original parents. In the study made by Das et al., (2005) tolerant genotypes were identified and key traits such as high levels of non-structural carbohydrates (NSC, starch and soluble sugars) and limited underwater elongation were found to be 
associated with tolerance. According to Sarkar et al., (2009) the submergence tolerance mechanism in respect to seedling height, carbohydrate, chlorophyll and specific leaf weight (SLW) was studied in rice. Twenty five-day-old seedlings of five rice cultivars were submerged for 12 days. Submergence tolerant cultivars consumed more carbohydrates in the beginning of submergence to elongate the seedling height and later produce new carbohydrates after exposure of the leaves in the sunlight above water. Moreover, they maintained more chlorophyll and specific leaf weight as compared with susceptible cultivars during submergence.

\section{Evaluation of Sub1 introgressed lines}

\section{Extent of genetic variation}

The analysis of variance revealed the existence of significant variation among the genotypes for grain yield and all other morpho-physiological quantitative characters. In case of morphological quantitative characters, high estimates of genotypic and phenotypic variation in the present study as revealed from the estimates of GCV and PCV's for stem thickness, panicle number per plant indicated that selection would be effective for these characters. The high estimates (>80\%) of heritability for these characters also indicated considerable genetic variation and lower influence of environment in the expression of these characters. These results were in accordance with De and Rao (1987), Deosarkar et al., (1989), Bai et al., (1992) and Ravindra Babu (1996). The difference between GCV and PCV values were relatively low in the present study, which indicated less influence of the environment for the characters. The GCV provides information for comparison of the genetic variability and indicates the validity of the traits for selection. However, it does not provide a clear picture of the extent of genetic gain to be achieved from selection unless heritable fraction of variation is known (Burton, 1952), indicating the importance of heritability estimation. Heritability in broad sense being the ratio of genotypic variance to phenotypic variance indicates the extent of genetic control of a given trait and thus reflects the efficiency of selection of the trait. High heritability with high genetic advance was reported for the characters like grain per plant, 100-grain weight and grain number by Deo sarkar et al., (1989). High heritability with high genetic advance for days to flowering was reported by Singh et al., (1986) and Roy et al., (1992).

For effective selection high heritability estimates coupled with high genetic advance is a better criterion as suggested by Panse $e t$ al., (1957). Genetic advance is dependent upon the heritability of trait, genetic variability and intensity of selection (1999). In the present investigation high magnitude of genetic advance as percent of mean $(>20)$ were observed for stem thickness (58.69), leaf length of blade (41.13), panicle no per plant (34.14), leaf width of blade (32.44), grain weight of 1000 fully developed grains (28.97), grain width (23.12) and yield (22.67). In the present study high heritability $(>80)$ with high genetic advance $(>20)$ as percent of mean estimates were recorded for leaf length of blade, stem thickness, leaf width of blade, grain weight of 1000 fully developed grains and grain width. High genetic advance coupled with high heritability estimates indicates that these traits are governed by additive gene and therefore, selection based on phenotypic performance is likely to give beneficial results in improving these characters. These results indicated the involvement of increased additive gene action and therefore, phenotypic selection without progeny testing to increase the frequency of additive gene will be effective to a certain 
extent. High heritability $(>80)$ with moderate genetic advance (10-20) was observed for traits like stem length, decorticated grain width. Moderate heritability (60-80) with low genetic advance $(<10)$ was observed for the traits like grain length and decorticated grain length whereas, moderate heritability (60-80) with high genetic advance (>20) was observed for traits like yield and panicle number per plant. The results corroborated with research conducted by Afrin et al., (2018). Low heritability with low genetic advance was not observed. This indicated that these characters might be under the small effect of control of non-additive (dominance and epistasis) gene action. Hence, these traits do not offer much scope for improvement through simple selection. The use of population improvement concept and intermittent biparental mating and relaxation of selection in segregating generations could help in generation of useful recombinants for improvement of such traits. Many workers emphasized the application of recurrent selection in addition to conventional selection methods in autogamous crops like rice (Singh and Singh, 1991). Amongst all the morphophysiological quantitative traits stem thickness and leaf length of blade was found to possess maximum genetic variation apparently controlled by additive genes. Thus this trait deserves top most priority in selection.

Submergence is a recurring problem where short term flash flooding damages rice in the rice-producing rainfed lowland areas. Developing rice cultivars with tolerance to submergence with yield and quality traits acceptable to farmers is a feasible approach to address this problem. Due to the heterogeneity in flood prone ecosystem many different types of traditional rice cultivars are being grown by the farmers. This necessitates development of high yielding varieties in popular rice variety background that are submergence tolerant and are more likely to be rapidly adopted by farmers in the target regions. The present investigation was carried out with the objective of phenotypic screening and evaluation of Subl introgressed lines for submergence tolerance in popular rice varieties (Ranjit and Bahadur) background. The Subl introgressed lines in Ranjit and Bahadur background have exhibited expression of Subl in submerged condition. The Subl introgressed lines can survive for more than 12 days of continuous submergence. There were significant variations in the Subl introgressed lines and therefore selection will be effective for further improvement.

\section{Acknowledgement}

Authors express thanks to Department of Biotechnology, Government of India for providing fund to carry out the experiments.

\section{References}

Afrin W, Nafis MH, Hossain MA, Islam MM and Hossain MA (2018) Responses of rice (Oryza sativa L.) genotypes to different levels of submergence. C R Biologies 341:85-96.

Allard RW (1960) Principles of plant breeding. John Wiley and Sons, New York.

Burton GW (1952) Quantitative inheritance in grasses. Proc. 15th Int Grassland Cong 1:227-283.

Burton GW and Devane EM (1953) Estimating heritability in tall fescus (Festuca arundinaceae) from replicated clonal material. Agron J 45:478-485.

Das KK, Sarkar RK, Ismail AM (2005) Elongation ability and non-structural carbohydrate levels in relation to submergence tolerance in rice. Plant Science 168:131-136. 
De RN, Suriya Rao AV (1987) Genetic variability and correlation studies in rice under semi-deep water logged situation. Oryza 25:360-364.

Deosarkar DB, Misal MB, Nerker YS (1989) Variability and correlation studies for yield and yield attributing characters in breeding lines of upland rice. $\mathrm{J}$ Maharastra Agric Univ 14:28-29.

Goswami S, Kar RK, Paul A, Dey N (2017) Genetic potentiality of indigenous rice genotypes from eastern India with reference to submergence tolerance and deep water traits. Curr Plant Biol 1112:23-32.

Hanson CH, Robinson HF, Comstock RE (1956) Biometrical studies of yield in segregating population of Korean Lespedeza. Agron J 48:267-282.

Iftekharuddaula KM, Ahmed HU, Ghosal S, Amin A, Moni ZR, Bisnu PR, Barman HN, Siddique MA, Collard BCY, Septiningsih EM (2016) Development of early maturing submergence tolerant rice varieties for Bangladesh. Field Crop Res 190:44-53.

Jena PP, Bharathkumar S, Reddy JN, Mohapatra T (2015) Introgression of Subl locus into highly preferred rice cultivars (Pooja and Pratikshya) in eastern region of India for submergence tolerance through marker assisted backcrossing. Adv Biores 6(1):45-53

John D, Shylaraj KS (2017) Introgression of Sub1 QTL into an elite rice (Oryza sativa $\mathrm{L}$.) variety Jyothi through marker assisted backcross breeding. Journal of Tropical Agriculture 55:1-11.

Mackill DJ, Ismail AM, Singh US, Labios RV, Paris TR (2012) Development and Rapid Adoption of Submergence Tolerant (Sub1) Rice Varieties. Advances in Agronomy 115.

Nandi S, Subudhi PK, Senadhira D, Manigbas NL, Sen Mandi S, Huang N (1997) Mapping QTLs for submergence tolerance in rice by AFLP analysis and selective genotyping. Mol Gen Genet 225:1-8.

Neeraja C, Rodriguez RM, Pamplona A, Heuer S, Collard B, Septiningsih E (2007) A marker-assisted backcross approach for developing submergencetolerant rice cultivars. Theor Appl Genetic 115:767-776.

Panse VG (1957) Genetics of quantitative characters in relation to plant breeding. Indian J of Genetics 17:318-327

Rama B, Regina A, Devika R, Joseph CA (1992) Genetic variability and association of characters in medium duration rice genotypes. Oryza 29:19-22

Ravindra Babu V (1996) Study of genetic parameters, correlations and path coefficient analysis of rice under saline conditions. Ann Agric Res 17:370-374.

Roy A, Kar MK (1992) Heritability and correlation studies in upland rice. Oryza 29:195-199.

Sarkar KR, De NR, Reddy NJ, Ramakrishnayya G (1996) Studies on the Submergence Tolerance Mechanism in Relation to Carbohydrate, Chlorophyll and Specific Leaf Weight in Rice (Oryza sativa L.). J Plant Physiol 149:623-625.

Sarkar RK, Reddy JN, Sharma SG, Ismail AM (2006) Physiological basis of submergence tolerance in rice and implications for crop improvement. Curr Sci 91:899-906.

Septiningsih EM, Pamplona MA, Sanchez DL, Neeraja CN, Chirravuri GV, Heuer S, Ismail AM, Mackill DJ (2009) Development of submergence-tolerant rice cultivars: the Subllocus and beyond. Ann Bot 103(2):151-160.

Singh R, and Singh A (1991). Combining ability for harvest index and other related characters in rice. Oryza 28:1922. 
Singh R, Singh Y, Xalaxo S, Verulkar S, Yadav N, Singh S, Singh N, Prasad KSN, Kondayya K, Rao PVR, Rani MG, Anuradha T, Suraynarayana Y, Sharma PC, Krishnamurthy SL, Sharma SK, Dwivedi, JL, Singh AK, Singh PK, Nilanjay, Singh NK, Kumar R, Chetia SK, Ahmad T, Rai M, Perraju P, Pande A, Singh DN, Mandal NP, Reddy JN, Singh ON, Katara JL, Marandi B, Swain P, Sarkar RK, Singh DP, Mohapatra T, Padmawathi G, Ram T, Kathiresan RM, Paramsivam K, Nadarajan S, Thirumeni S, NagarajanM, Singh AK, Vikram P, Kumar A, Septiningshih E, Singh US, Ismail AM, Mackill D, Singh NK (2016) From QTL to variety harnessing the benefits of QTLs for drought, flood and salt tolerance in mega rice varieties of India through a multi-institutional network. Plant Sci 242:278-287

Singh RK, Chaudhary BD (1999) Quantitative Genetics Analysis. Timberland Publishers, New Delhi, India Pp 180

Singh RS, Chauhan SP, Maurya DM (1986) Genetic variability in 98 upland rice cultivars of India. IRRN 11(4): 9-10

World Bank (2008) Climate Change Impacts in Drought and Flood Affected Areas: Case Studies in India. Report No. 43946:1-162

Xu K, and Mackill DJ (1996) A major locus for submergence tolerance mapped on rice chromosome 9. Mol Breed 2:219224.

\section{How to cite this article:}

Ashish Gautam, S.K. Chetia, M.K. Modi and Ahmed, T. 2018. Phenotypic Screening and Evaluation of Sub1 Introgressed Lines in Popular Rice Varieties Ranjit and Bahadur of Assam, India. Int.J.Curr.Microbiol.App.Sci. 7(09): 1744-1755. doi: https://doi.org/10.20546/ijcmas.2018.709.211 